\section{Cue properties vs palatability of flavors in avoidance learning*}

\author{
JOHN GARCIA and RICHARD KOVNER \\ State University of New York, Stony Brook, N.Y. 11790 \\ and \\ KENNETH F. GREEN \\ California State College, Long Beach, Calif. 90804
}

When a flavor is immediately followed by peripheral electric shock, rats learn to use the flavor cue to avoid shock, but ingestion of that flavor is not reduced outside the shock apparatus. In contrast, when a flavor is followed by internal illness, rats will reject that fluid in or out of the situation where illness occurred. However, motor approach to visual cues previously associated with that flavor is not immediately affected. Thus flavor, used as a cue, acquires generalization properties depending upon the subsequent reinforcer and reflecting differential specialization in mechanisms controlling palatability and locomotor responses.

Not all combinations of signals and punishments are effective in avoidance training of animals. Rats will maintain or increase their intake of a distinctively flavored food previously paired with electrocutaneous shock, but will markedly decrease their consumption if this flavor has been paired with illness induced by injections or X-rays. Conversely, when flavor is held constant, they will hesitate to approach a visually distinctive food that has been previously paired with shock, but will approach and eat this food readily if it has been followed by illness (Garcia \& Koelling, 1966; Garcia et al, 1968). These results suggest that central mechanisms controlling palatability, ingestion, and malaise differ from those integrating external signals, locomotion, and cutaneous insults, and that it may be difficult to reduce palatability with contingent shock. However, it may be possible to use a flavor to signal locomotor avoidance of shock without depressing its palatability. Furthermore, if a flavor is suddenly made unpalatable, ingestion may be depressed without immediate inhibition of locomotor approach towards cues leading to that flavor.

\section{METHOD}

Two experiments were conducted to test these implications. Young adult male rats (approximately $400 \mathrm{~g}$ ) maintained in individual cages, were habituated to handling and drinking once each day for 2 weeks before training began. Flavor stimuli consisted of saccharin water $(1.0 \mathrm{~g}$ saccharin per liter) or salty water $(7.0 \mathrm{~g}$ $\mathrm{NaCl}$ per liter). These solutions were about equally preferred to each other and both were preferred to unflavored water. After training, posttests of fluid intake were conducted in the usual balanced order; half

*Research supported by NIH Grant EC 00132 the animals were tested first in the apparatus and then in their home cages, and the other half were treated conversely.

Experiment $\mathrm{A}$ was conducted to determine if an animal could be taught to avoid electric shock to the paws in a gray shuttlebox ( $5 \times 36$ in., with 8 -in. walls) where flavors provided the only available cues, and if so, to determine what effect the flavor-shock association would have upon preference for those flavors outside of the shuttlebox. For six rats, salty water was the shock fluid and saccharin was the safe fluid, while five rats were treated conversely. Each thirsty rat was placed in the center of the shuttlebox and allowed to select a drinking spout at either end. When the rat selected the shock fluid, he was shocked within $2.0 \mathrm{sec}$ of his first lick at the spout with a single pulse to the paws via the floor grid and a constant current source at a minimal intensity (about $0.2 \mathrm{sec}$ at $2.0 \mathrm{~mA}$ ) sufficient to interrupt drinking without producing excessive fear. If a rat persisted in drinking the shock fluid, shocks were repeated and, if necessary, intensity was increased until the rat "corrected itself" by going to the other end, where it was allowed to drink the safe fluid for at least $2 \mathrm{~min}$. If the rat initially chose the safe fluid, it was allowed to drink undisturbed for a similar period. Two to four trials were given daily. Between trials flavors were switched according to a random schedule, given that the shock fluid appeared no more than three consecutive times at the same end and an equal number of times at both ends in a run of 20 trials. After training, preference tests for the two fluids were tested in (1) four 3-min shock-free trials in the shuttlebox and (2) one 20-min trial in the home cage with two bottles, after animals were allowed to sample both fluids.

Experiment B was conducted to test approach reactions to visual cues previously associated with a preferred (saccharin) solution after that flavor was made aversive by pairing it with illness in another situation. Animals were trained in a T-maze composed of narrow (5-in.) alleys and high (18-in.) walls. The 18-in. gray stem led to a choice point with a black right and white left arm, each 18 in. long. Our rats displayed the well-known preference for black over white; thus all animals were rewarded with the preferred saccharin in the nonpreferred white left arm of the maze. Water was always provided in the black arm. During the first part of training (Trials 1 to 40) each thirsty rat was given a free choice between the black (water) arm and the white (saccharin) arm, followed by a forced-choice trial to the opposite side to insure that it sampled both fluids. Only the free-choice responses were scored as a measure of learning. Initially the animals were given two trials per day with a $30-\mathrm{sec}$ drink and later four trials with a 10-sec drink.

After all animals had learned to select the white arm for saccharin, maze trials were suspended for 8 days of aversion conditioning. On Day 1 all rats received water in their home cages for their 10-min drinking period. On Day 2 they received saccharin and 10 min later they were given a toxic injection $(8.0 \mathrm{ml}$ of $.12 \mathrm{M} \mathrm{LiCl} \mathrm{IP})$ which produces a mild illness (inactivity, anorexia). On Day 7 the treatment was repeated. Water was provided on all other days. On Day 9 maze trials were resumed. After the toxic treatment and maze training, the animals' ingestion of saccharin water and tap water were tested in 10-min single-bottle tests in the maze goalbox and in the home cages.

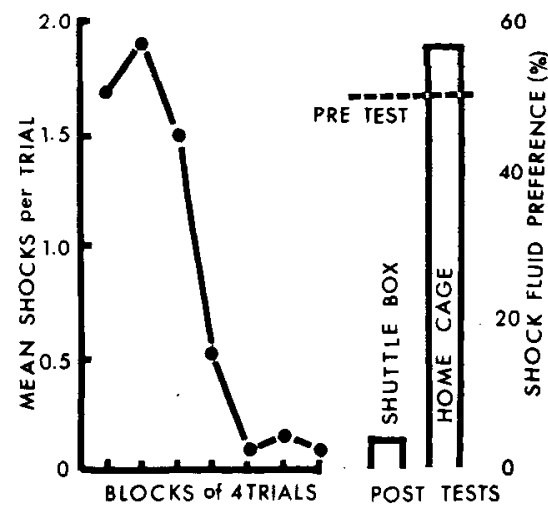

Fig. 1. Experiment A. The graph (left) illustrates mean shocks per trial as rats learned to use a flavor cue to avoid shock in a shuttlebox. The bars (right) indicate their preference for the shocked fluid in two places after flavor-shock training. [This difference is significant $(p<0.01)$.] 


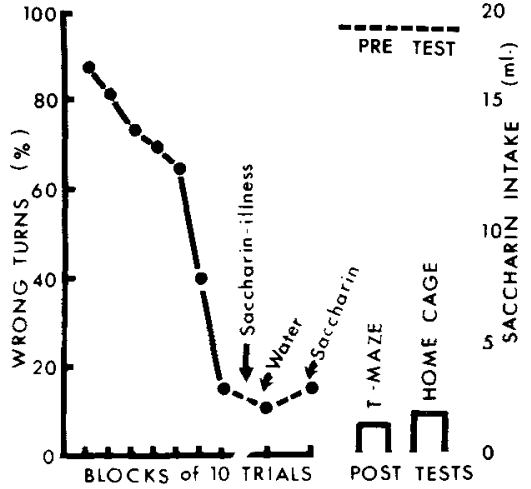

Fig. 2. Experiment B. The graph (left) illustrates mean errors per 10 -trial block as rats learned to obtain saccharin-water in the right (white) arm of a T-maze. The "water" and "saccharin"points indicate turns in two test blocks, where water then saccharin was available in that arm following flavor-illness pairing. The bars (right) indicate ingestion in two places after that pairing. [This difference is not significant $(p<0.05)$.]

\section{RESULTS AND DISCUSSION}

These experiments indicate that flavors, when used as cues, acquire generalization properties that reflect the nature of the reinforcer and the performance required of the animal. In Experiment A (Fig. 1), the animals learned to use flavor to avoid the peripheral insult of shock in 20 to 28 trials, a performance that compares favorably with shuttlebox avoidance when visual or acoustical cues are used. ${ }^{1}$ The rats learned to approach the spout cautiously, stretch their necks, sniff, and lick gingerly. If the bottle contained the shock fluid, they quickly turned and went to the bottle at the other end of the box; if it contained the safe solution, they drank steadily. Under these conditions, the flavor cues, like external signals, apparently require immediate reinforcement and are probably subject to the same contextual and distractive influences that affect external signals.
However, ingestion of the shocked fluid is not reduced outside of the spatiotemporal context of the shock. This is supported by preference tests outside the apparatus in Experiment A (Fig. 1) and in the previous experiments in which the animals were tested in the apparatus but under extinction conditions, i.e., when shock was not applied in its usual temporal sequence (Garcia et al, 1968).

In contrast, when a flavor is followed by internal malaise, the animals ingestion of that flavor is reduced even in situation where the illness was not induced. Although training was prolonged in Experiment B (Fig. 2) due to the high initial preference for the black arm of the T-maze with its unsweetened water, the thirsty rats eventually learned to select the white arm for saccharin. They persisted in selecting the white (saccharin) arm even after the conditional pairing of saccharin illness, whether the white arm now contained water which they drank or saccharin which they merely sampled. Apparently, prolonged "reversal training" would be required to teach the animals that the visual-spatial cues of the white arm now led to an aversive flavor.

Furthermore, postillness tests (Fig. 1) revealed a marked decrement in saccharin intake in the T-maze, where they had never been made ill, as well as in the home cages. This substantiates previous studies which demonstrated that contextual place cues associated with illness have little effect upon ingestion or preference (Garcia \& Ervin, 1968; Rozin, 1969) and that immediate reinforcement is not required when toxic agents are used to establish changes in palatability of flavors (Garcia, Ervin, \& Koelling, 1966; Smith \& Roll, 1967; Revusky, 1968).

Rats act as if they inferred that flavors might be "merely associated" with peripheral pain in space and time but could "actually cause" illness. Similar behavior has been reported by Brower (1969) for bluejays that became ill after eating toxic monarch butterflies. We believe that this reflects differential specialization in the adaptive mechanisms for the external and internal environments. In a previous paper (Garcia \& Ervin, 1968) convergence of the taste and visceral afferents to the nucleus of the tractus solitarius was proposed as the integrative mechanism by which flavors and visceral illness are specifically associated over long interstimulus intervals to adjust palatability. The present data suggests that the taste information must also diverge to other integrative centers where it can be used, under the same spatiotemporal constraints as external stimuli, to guide locomotor avoidance responses.

\section{REFERENCES}

BROWER, L. P. Ecological chemistry. Scientific American, 1969, 220, 22-29.

GARCIA, J., \& ERVIN, F. R. Gustatory-visceral and telereceptor-cutaneous conditioning, adaptation in internal and external milieus. Communications in Behavioral Biology, 1968, 1, 389-415.

GARCIA, J., ERVIN, I: R., \& KOELLING, R. A. Learning with prolonged delay of reinforcement. Psychonomic Science, 1966, 5, 121-122.

GARCIA, J., \& KOELLING, R. A. The relation of cue to consequence in avoidance learning. Psychonomic Science, 1966, 4, 123-124.

GARCIA, J., McGOWAN, B. K., ERVIN, F. R. \& KOELLING, R. A. Cues-their relative effectiveness as a function of the reinforcer. Science, 1968, 160, 794-795.

REVUSKY, S. H. Aversion to sucrose produced by contingent $X$-irradiation-temporal and dosage parameters. Journal of Comparatjve \& Physiological Psychology, 1968, 65, 17-22.

ROZIN, P. Central or peripheral mediation of learning with long CS-US intervals in the feeding system. Journal of Comparative \& Physiological Psychology, 1969, 67, 421-429.

SMITH, J. C., \& ROLL, D. L. Trace conditioning with $X-r$ ays as the aversive stimulus. Psychonomic Science, 1967. 9, 11-12.

$$
\text { NOTE }
$$

1. A brief discussion of Experiment A will appear in Revusky, S. H., \& Garcia, J., Learned associations over long delays. In G. Bower and J. T. Spence (Eds.), The psychology of learning and motivation. Vol. 4. New York: Academic Press (in press). 